\title{
Health Literacy and Informed Consent Materials: Designed for Documentation, Not Comprehension of Health Research
}

\section{Authors: Vanessa Watts Simonds, Eva Marie Garroutte, and Dedra Buchwald}

This is an Accepted Manuscript of an article published in Journal of Health Communication July 2017, available online:

http://www.tandfonline.com/10.1080/10810730.2017.1341565

Simonds, Vanessa Watts, Eva Marie Garroutte, and Dedra Buchwald. "Health Literacy and Informed Consent Materials: Designed for Documentation, Not Comprehension of Health Research." Journal of Health Communication 22, no. 8 (September 2017): 682-691. DOI: 10.1080/10810730.2017.1341565.

Made available through Montana State University's $\underline{\text { ScholarWorks }}$ scholarworks. montana.edu 


\title{
Health Literacy and Informed Consent Materials: Designed for Documentation, Not Comprehension of Health Research
}

\author{
VANESSA WATTS SIMONDS ${ }^{1}$, EVA MARIE GARROUTTE ${ }^{2}$, and DEDRA BUCHWALD ${ }^{3}$ \\ ${ }^{1}$ Department of Health and Human Development, Montana State University, Bozeman, Montana, USA \\ ${ }^{2}$ Department of Sociology, Boston College, Boston, Massachusetts, USA \\ ${ }^{3}$ Initiative for Research and Education to Advance Community Health, Washington State University, Seattle, Washington, USA
}

\begin{abstract}
Minority populations with health disparities are underrepresented in research designed to address those disparities. One way to improve minority representation is to use community-based participatory methods to overcome barriers to research participation, beginning with the informed consent process. Relevant barriers to participation include lack of individual or community awareness or acceptance of research processes and purposes. These barriers are associated with limited health literacy. To inform recommendations for an improved consent process, we examined 97 consent documents and 10 associated Institutional Review Board websites to determine their health literacy demands and degree of adherence to principles of community-based research. We assessed the reading level of consent documents and obtained global measures of their health literacy demand by using the Suitability and Comprehensibility Assessment of Materials instrument. Although these documents were deemed suitable as medical forms, their readability levels were inappropriate, and they were unsuitable for educating potential participants about research purposes. We also assessed consent forms and Institutional Review Board policies for endorsement of community-based participatory principles, finding that very few acknowledged or adhered to such principles. To improve comprehension of consent documents, we recommend restructuring them as educational materials that adhere to current health literacy guidelines.
\end{abstract}

Even though members of racial and ethnic minorities experience an unequal burden of many common illnesses, including cancer, cardiovascular disease, and diabetes, these groups remain underrepresented in research designed to prevent and treat such illnesses (Chen, Lara, Dang, Paterniti, \& Kelly, 2014; Hawk et al., 2014). The inadequate participation of women and minorities in clinical research prompted the National Institutes of Health Revitalization Act of 1993 (P.L. 103-43) and its update in 2001, which offered guidelines for the inclusion of these demographic categories. Nevertheless, the representation of racial and ethnic minorities in research funded by the National Institutes of Health still falls short of proportionality (Chen et al., 2014; Ford et al., 2013; Hawk et al., 2014).

Several studies have sought strategies to increase research participation by underrepresented groups (Ford et al., 2013; George, Duran, \& Norris, 2014; Schmotzer, 2012). Many of the barriers and facilitators identified in these studies are consistent with a conceptual model developed to understand how to improve the recruitment of minority women in research (Brown, Long, Gould, Weitz, \& Milliken, 2000). This model identifies

Address correspondence to Vanessa W. Simonds, Department of Health and Human Development, Montana State University, 316 Herrick Hall, Bozeman, MT 59717-3540, USA.

E-mail: vanessa.simonds@montana.edu three factors governing decisions to participate: individual-level awareness of the purpose, processes, and importance of research; community-level acceptance of research; and individual and community perceptions of the ease of access to research activities. Health literacy is implicated in all three factors, especially during the process of obtaining consent for research participation. The authors advised investigators to communicate more effectively with potential participants, including the provision of understandable consent forms (Brown et al., 2000).

Although not intentionally deceptive, consent forms often use complex language and are designed primarily to document agreement to participate rather than to ensure that participants understand the proposed research (Grady, 2015; Lorenzen, Melby, \& Earles, 2008). Indeed, previous studies report that clinical trial participants might have limited understanding of the experimental aspect of such efforts(Corbie-Smith, Thomas, Williams, \& Moody-Ayers, 1999; Flory \& Emanuel, 2004; Nishimura et al., 2013; Putnam et al., 2015; Tattersall, 2001; Trantham et al., 2015). Without clear communication about the purpose, process, and benefits of specific studies, community members might not be aware of their importance. In addition, the lack of readily understandable consent forms directly affects their access to research (Brown et al., 2000). Even though Institutional Review Boards (IRBs) play an important role in setting standards for informed consent, they often approve documents that do not conform to their own readability guidelines (Paasche-Orlow, Taylor, \& Brancati, 2003). 
Reading skills are a component of health literacy as well as of literacy per se. Limited literacy is most prevalent in racial and ethnic minorities, older and less educated adults of all races, and people with poorer self-rated health (Goodman et al., 2013; Kirsch, Jungeblut, Jenkins, \& Kolstad, 2002). According to the Program for International Assessment of Adult Competencies in 2012, literacy skills in the general US population have not improved since the 1992 National Adult Literacy Survey (Goodman et al., 2013; Kirsch et al., 2002; Kutner, Greenberg, Jin, \& Paulsen, 2006). In the most recent assessment, one in six adults had low literacy skills.

People with limited health literacy have less health knowledge and experience poorer health outcomes than their more health-literate counterparts (Aboumatar, Carson, Beach, Roter, \& Cooper, 2013; Margolis, Hampton, Hoffstad, Malay, \& Thom, 2015; Moser et al., 2015; Quinlan et al., 2013). Accordingly, the need for clear communication is recognized by investigators working with members of vulnerable populations (Sudore et al., 2006), who cite misperceptions of the purpose and procedures of clinical trials as a key barrier to research participation (Braunstein, Sherber, Schulman, Ding, \& Powe, 2008; Evans, Lewis, \& Hudson, 2012; Ford et al., 2005; George et al., 2014). This and similar barriers are more prevalent in underserved communities. Incorporating community-based participatory research (CBPR) methods in recruitment, informed consent, and retention strategies can help to overcome these barriers and enhance minority access to, awareness of, and especially acceptability of research participation (De las Nueces, Hacker, DiGirolamo, \& Hicks, 2012; Paskett et al., 2008; Seifer, Michaels, \& Collins, 2010; Simonds, Wallerstein, Duran, \& Villegas, 2013). A CBPR approach advises that consent forms be approved by relevant community leaders, that they articulate how research data will be used and who can access it, and that they describe the community-level risks and benefits of proposed studies (Flicker, Travers, Guta, McDonald, \& Meagher, 2007). However, few university IRBs adhere to these guidelines (Flicker et al., 2007).

Our study had four objectives: 1) to evaluate the health literacy demands of the informed consent documents (ICDs) by scoring them in terms of their suitability for the intended audiences, 2) to compare suitability scores to the level of health literacy recommended by IRB policies, 3) to examine the extent to which the ICDs incorporated relevant CBPR principles, and 4) to compare the resulting ICDs level of CBPR incorporation with the guidance offered by their respective IRBs.

\section{Methods}

To inform recommendations for an improved consent process, we examined ICDs created for studies conducted under the auspices of the Centers for Population Health and Health Disparities initiative and approved by their IRBs. Ten Centers encompassing 12 academic institutions were funded by the National Cancer Institute and the National Heart, Lung, and Blood Institute from May 2010 through April 2015. All Centers used CBPR methods and focused exclusively on underserved US populations, which are typically characterized by low socioeconomic status, low educational attainment, multiple clinical and psychosocial comorbidities, and poor health literacy (National Center for Education Statistics, 2003, 2013; Schillinger et al., 2002). The Centers' service populations included Latinos/Hispanics, American Indians/Alaska Natives, African-Americans, and residents of Appalachia. We reviewed their ICDs, as well as the templates on which they were based, in terms of their health literacy demands and their correspondence with CBPR principles. We also reviewed the IRB policies governing each Center's ICDs.

\section{Setting and Document Collection}

In 2013, we contacted all 10 Principal Investigators of the Centers for Population Health and Health Disparities and requested the ICDs for all studies described in their original applications. These included letters, brochures, information sheets, and informed consent forms. The latter included consent forms created for interviews, focus groups, medical record review, collection of biospecimens, and combinations of procedures.

\section{Informed Consent Documents}

We categorized ICDs by type of material and evaluated each one for health literacy attributes and alignment with CBPR principles, as described below.

\section{Readability}

The Simple Measure of Gobbledygook (SMOG) is a widely endorsed instrument that offers a readability formula recommended for use in health care (Wang, Miller, Schmitt, \& Wen, 2013). This validated, reliable measure is calculated by counting the number of words with three or more syllables in 10 consecutive sentences selected from the beginning, middle, and end of the text. The count is then converted to an approximate grade level by using the validated SMOG conversion table.

\section{Suitability and Comprehensibility}

The Suitability and Comprehensibility Assessment of Materials $(\mathrm{SAM}+\mathrm{CAM})$ is a validated, reliable tool to assess text-based materials for use by people with low health literacy. It has been successfully applied to ICDs (Helitzer, Hollis, Cotner, \& Oestreicher, 2009). It scores materials as 0 (not suitable), 1 (adequate), 2 (superior), or "not applicable" in each of 22 variables in six categories: content, literacy demand, numeracy, graphics, layout/typography, and learning stimulation/motivation. The final SAM+CAM score is calculated by dividing the total number of points scored by the total number of possible points to yield a percentage (Helitzer et al., 2009). We applied the $\mathrm{SAM}+\mathrm{CAM}$ as its creators recommend for health system materials, excluding the sixth category (learning stimulation/ motivation) as well as two variables in the remaining categories that are not applicable to ICDs (summary/review and illustrations). These exclusions resulted in the following five categories, which collectively encompass 13 variables:

1. Content refers to the presence of explicit information about the purpose of the study and the behaviors desired of participants. 
2. Literacy demand assesses vocabulary, phrasing, and logical organization.

3. Numeracy refers to the use of numbers, fractions, percentages, and calculations.

4. Graphics refers to the inclusion and design of illustrations, tables, and graphs. SAM+CAM uses two variables for this category: appropriateness of illustrations and clarity of tables and charts. We excluded the Illustration variable and focused on evaluating tables and charts as suggested by Helitzer and colleagues (2009). Tables and charts are assessed on ease of understanding and inclusion of explanatory captions or "how to" instructions.

The creators of SAM+CAM recommend using the validated PMOSE/IKIRSCH document readability formula (Mosenthal \& Kirsch, 1998) to score the complexity of tables and charts. The PMOSE/IKIRSCH score is then factored into the SAM+CAM score. For PMOSE/IKIRSCH, the complexity of a table is defined by two factors: structure and density. These refer to the number of "labels" or headings used for columns and rows (structure) and the number of "items" or individual data cells (density). Higher scores denote higher literacy demands, with scores grouped into four categories: "very low" (4 to 8 years of schooling); "low" (8 to 12 years); "moderate" (12 to 14 years); and "very high" (16 years or post-bachelor's degree).

5. Layout/typography refers to the spatial and visual organization of text. Higher SAM+CAM scores are given to documents that use wide margins and ample white space to minimize density, topic headings to organize content, and appropriate font sizes and styles to enhance readability.

\section{Alignment with CBPR Principles}

Using a published statement of CBPR principles (Israel, Schulz, Parker, \& Becker, 1998), we developed a checklist of criteria to determine whether the ICDs addressed community-level principles by offering specific kinds of information as follows: 1) definition of the community, 2) a requirement for communitylevel approval, 3) a statement that the community has control over research data, 4) process for communities to withdraw from the study, and 5) a statement of community-level risks and benefits.

\section{Scoring}

The first author trained two research assistants to apply SMOG, $\mathrm{SAM}+\mathrm{CAM}$, PMOSE/IKIRSCH, and the checklist of CBPR principles. To ensure accuracy, both research assistants consulted with the first author as they worked. Each one independently applied these assessments to score the ICDs, and then, both discussed and resolved any discrepancies among themselves to achieve inter-rater consensus.

\section{IRB Website Analysis}

\section{Codebook and Review Process}

We developed a codebook to assess whether the institutional websites that provided IRB policies included recommendations consistent with our five health literacy categories or mentioned relevant CBPR principles. Then, in May and June 2014, we visited each site and evaluated the IRB policies. Two sites were excluded because they were restricted to internal users. Starting with each participating institution's main IRB website, the two research assistants independently timed how long it took to access instructions for consent forms. Then, they spent a maximum of 20 minutes extracting sample text that illustrated codebook categories. Three areas were evaluated: consent form templates, health literacy criteria, and CBPR principles.

We calculated SMOG scores for consent form templates because investigators use them to develop their own consent forms. Thus, templates with high literacy demands are likely to yield consent forms with similarly high demands. The SMOG score served as a proxy indicator of the corresponding IRB's attention to literacy demands. Then, we searched the text at each website for key words related to our five health literacy categories. We noted all references to each category and recorded IRB recommendations verbatim. Finally, we assessed whether each website mentioned a CBPR or a contact person for CBPR projects and whether the website addressed community-level principles 1) definition of the community, 2) a requirement for community-level approval, 3) a statement that the community has control over research data, 4) process for communities to withdraw from the study, and 5) a statement of community-level risks and benefits.

\section{Comparisons between IRB Websites and ICDs}

We used SPSS 24.0 (IBM Corp., Released 2016) to calculate Spearman correlations between the number of criterion mentioned by each Center's IRB website and mean SAM+CAM scores for ICDs produced by that Center.

\section{Results}

\section{Sample Description}

We collected 107 ICDs used by 32 research studies at 10 Centers. After excluding 10 ICDs in the form of scripts intended to be read aloud, our final sample comprised 97 ICDs, as detailed in Table 1 . The largest single category of ICDs comprised consent forms for adult research participants $(n=49)$. Other categories comprised assent forms for adult and child participants and consent and assent forms for clinic staff and providers. Also included in our ICD sample were 20 addenda in the form of brochures, letters, and flyers.

\section{Scoring Informed Consent Documents}

\section{Readability}

The mean SMOG score for all ICDs was grade 12 (standard deviation 1.9, range 8-16). Across types of ICDs, mean SMOG scores ranged from grade 9.7 through grade 16 (Table 1). Across Centers, mean SMOG scores ranged from grade 10.1 through grade 13.7 (Table 2).

\section{Suitability and Comprehensibility}

The frequency of SAM+CAM scores for each type of ICD is shown in Table 1. SAM+CAM scores by Center are shown in Table 2. No ICDs were scored as "not suitable," while 37 (38\%) were scored as "adequate" and 60 (62\%) as "superior." 


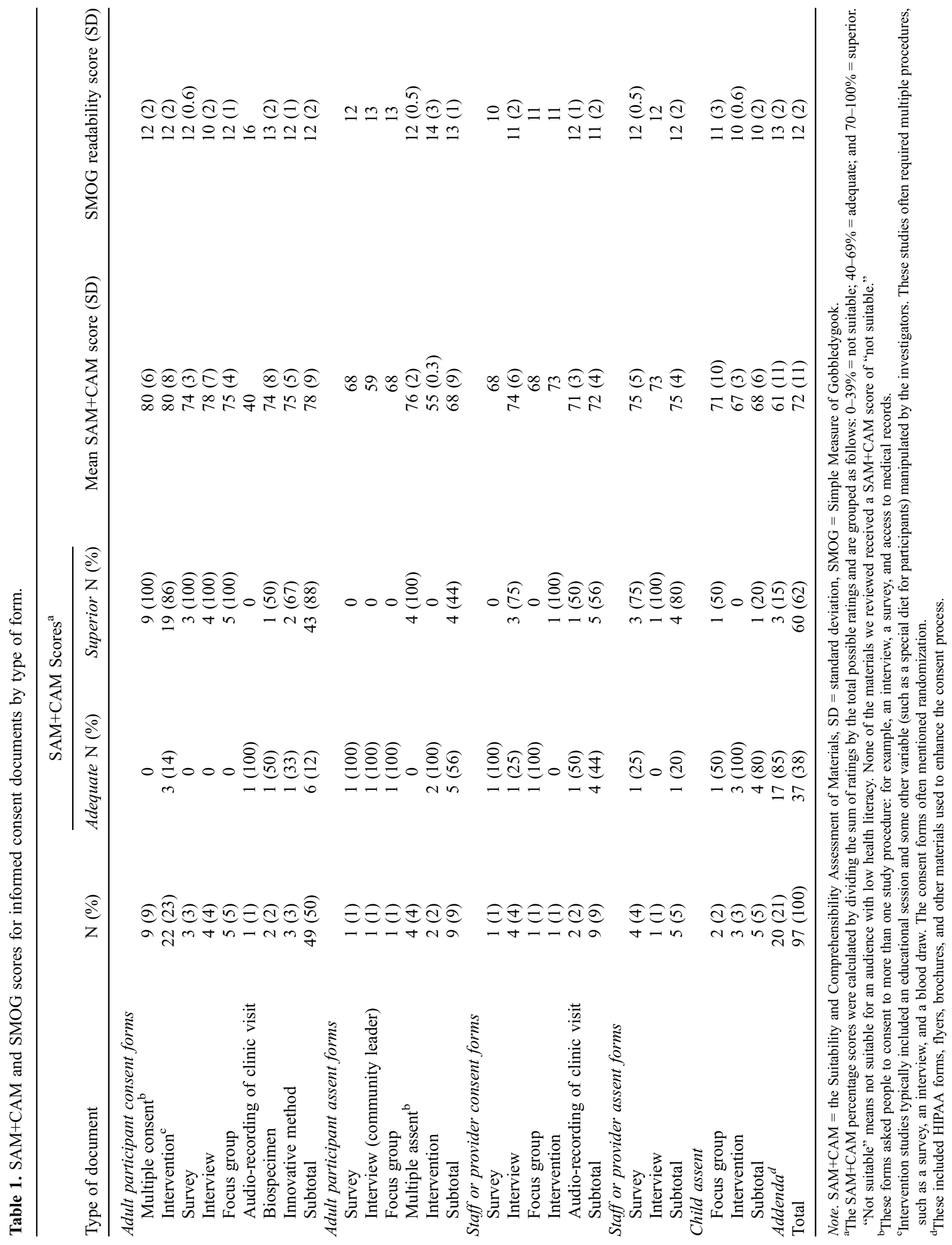




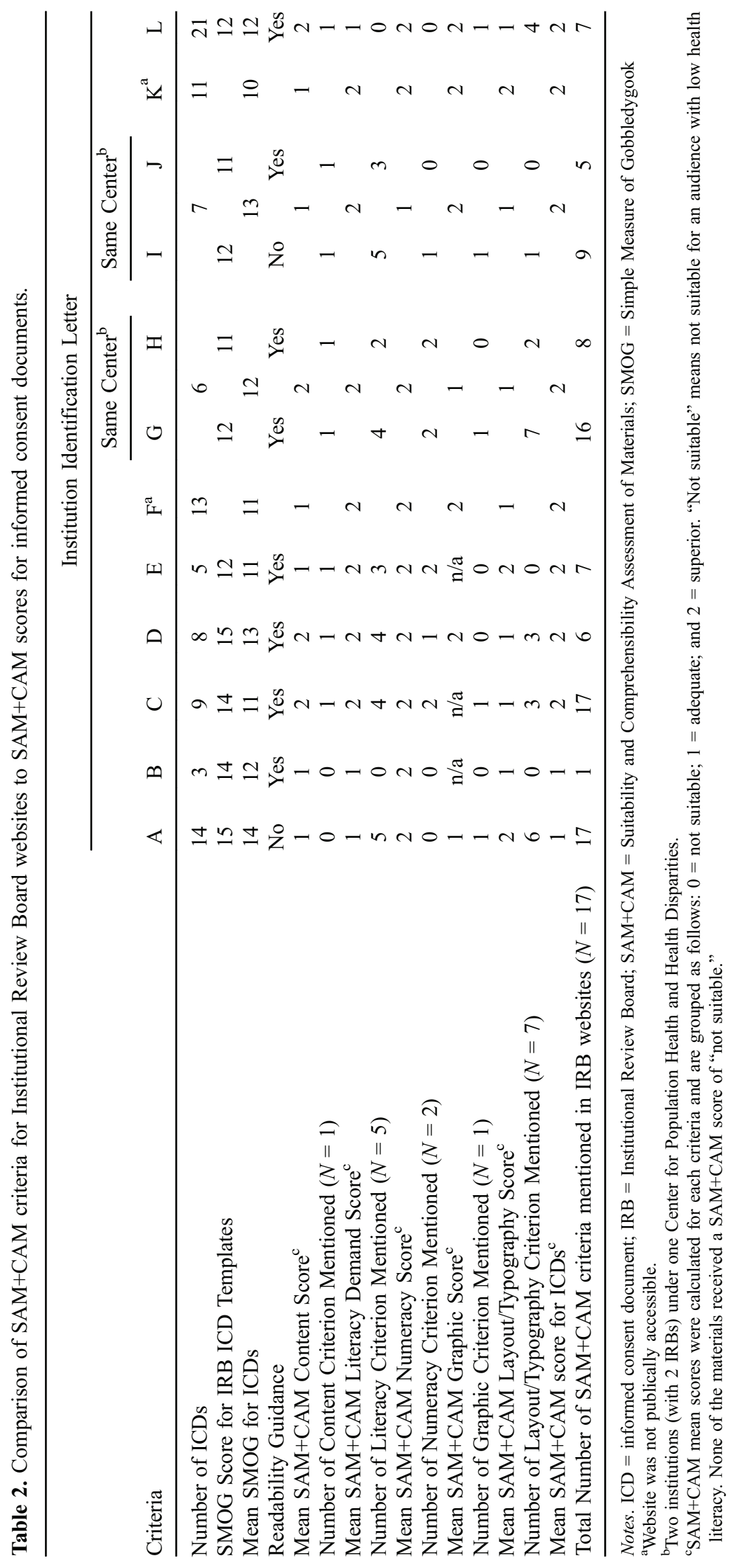


Individual components of the $\mathrm{SAM}+\mathrm{CAM}$ score revealed wider variability (Table 3 ).

1. Content. In this category, a high score requires an explicit statement of the purpose of the research and a clear description of the actions and behaviors desired of participants. Most ICDs $(72 \%)$ fulfilled these criteria, consistent with the fact that such information is a standard requirement for ICDs. However, $18 \%$ of ICDs were scored as "not suitable," typically because they were addenda that requested additional consent. For example, one addendum asked participants for permission to contact their pharmacist to obtain information about prescription medications. These ICDs were often short and lacked an explicit statement of purpose.

2. Literacy demand. In this category, $29 \%$ were scored as "adequate" and $71 \%$ as "superior." ICDs that included "confusion reducers" (explanatory expressions and analogies, avoidance of ambiguous pronouns) and "vocabulary helpers" (plain-language terms and examples) tended to have better scores. Overall, 53\% of ICDs used and defined at least one specialist term, and $82 \%$ used at least one specialist term that was not defined. Among defined terms were confidentiality, IRB, BMI, HIPAA, and randomized; among undefined terms were risk, catalyst, brachial artery, and anthropometry.

3. Numeracy. Of the 85 ICDs that used numbers, $92 \%$ were scored as "superior" for numeracy and $8 \%$ as "adequate." ICDs typically included numbers to express time, the count of research participants, and the dollar amount of incentives. Even though one ICD provided an example of a simple calculation, it still received a "superior" score. All "adequate" scores were due to the use of fractions or percentages that increased numeracy demand.

4. Graphics. ICDs scored as "superior" made limited use of tables and charts. "Superior" scores were also associated with relatively simple tables and charts (i.e., those with low PMOSE/IKIRSCH scores) that included explanatory captions. Five ICDs used tables to describe risks or study procedures, and two used flow charts to describe procedures. All these were assessed as appropriate for people with low educational levels. One ICD requested dates and locations of pharmacy use, requiring "moderate" education (i.e., college level). Another ICD included tables that were blank and required participants to provide information, such as their medications and the name of their pharmacy. These tables resulted in a level of complexity that reduced the overall SAM+CAM score to "adequate." We also scored 27 ICDs that required participants to provide other types of information. For example, one ICD stated, "I allow you to store any leftover blood and urine for future research," followed by checkboxes and a space for the date. Because this information was required for study purposes and because the format was scored as "very easy to understand" by PMOSE/IKIRSCH, the corresponding SAM +CAM score was "superior."

5. Layout/typography. In this category, $3 \%$ of ICDs were scored as "not suitable," $66 \%$ as "adequate," and $31 \%$ as "superior." Low scores typically resulted from overly dense text, while higher scores were associated with font sizes of at least 12 points, avoidance of narrow font styles, and the use of subheadings and lists to improve document organization.

\section{CBPR Principles}

Six ICDs $(6 \%$ of the total) provided by four centers defined the study community. However, only two ICDs referred to potential community-level benefits, and only the ICDs for a single Center studying American Indian/Alaska Native health mentioned community-level approval. None of the ICDs discussed communitylevel risks and benefits or set forth a process for community withdrawal from research participation.

\section{IRB Website Review}

\section{$S A M+C A M$}

For the 10 publicly available websites, research assistants needed a mean of 58 seconds to access IRB instructions (range 30-120 seconds). Eight sites recommended a reading level of grade 8 for ICDs (see Table 4). All provided sample consent form text, for which the mean reading level across sites was grade 12 (range 11-13). One site provided guidance on all the health literacy variables that we assessed, and one provided guidance on reading level only.

\section{CBPR Principles}

None of the IRB websites mentioned CBPR principles in their policies or guidance on ICDs.

\section{Comparison of IRB Website Criteria and ICDs by Center}

(Table 3). We found no correlation between mean SMOG scores for ICDs and mean SMOG scores for IRB templates for ICDs (Table 3). However, the mean SMOG scores for ICDs from Centers that offered guidelines on readability were superior to those from Centers that did not (grade 12 vs. grade 13.5, $\mathrm{p}<0.05)$. In addition, Centers that did not offer guidelines regarding a statement of the purpose of research had significantly lower SAM+CAM scores in the content category.

\section{Discussion}

We examined the health literacy demands and adherence to CBPR principles of 97 ICDs created by the Centers for Population Health and Health Disparities. We also reviewed the IRB policies that governed these documents, as stated on websites associated with the same Centers. Although most IRB policies recommended a reading level of grade 8 , in agreement with specialists in health literacy (Doak, Doak, \& Root, 1996), all ICDs in our sample exceeded that level. Likewise, the consent form templates provided by IRBs imposed a remarkably high literacy demand, with an average reading level of grade 12 . These findings surprised us, because all the Centers we examined conduct community-based research with underserved populations. We expected their ICDs to be more readily comprehensible than those designed for less diverse populations, which have been the focus of previous work. Nevertheless, many studies have reported that ICDs often exceed the grade 8 reading level, regardless of their priority populations (Kass, Chaisson, Taylor, \& Lohse, 2011; Paasche-Orlow et al., 2003; Terblanche \& Burgess, 2010; Terranova et al., 2012).

Our use of SAM+CAM enabled us to conduct a more comprehensive assessment of health literacy than most prior studies, 
Table 3. SAM + CAM scores by category.

\begin{tabular}{llllll}
\hline SAM+CAM category & \multicolumn{1}{c}{$\begin{array}{c}\text { Materials } \\
\text { assessed, } N(\%)\end{array}$} & $\begin{array}{c}\text { Not } \\
\text { suitable, } N \\
(\%)\end{array}$ & $\begin{array}{c}\text { Adequate, } \\
N(\%)\end{array}$ & $\begin{array}{c}\text { Superior, } \\
N(\%)\end{array}$ & $\begin{array}{c}\text { Mean SAM+CAM } \\
\text { score (SD) }\end{array}$ \\
\hline $\begin{array}{l}\text { Content (purpose, summary, credibility, desired reader } \\
\text { behavior) }\end{array}$ & $97(100)$ & $17(17.5)$ & $10(10.3)$ & $70(72.2)$ & $71.7(30.5)$ \\
$\begin{array}{l}\text { Literacy demand (writing style, vocabulary helpers, } \\
\quad \text { confusion reducers, context, scope, length) }\end{array}$ & $97(100)$ & 0 & $28(28.9)$ & $69(71.1)$ & $70.8(13.0)$ \\
$\begin{array}{l}\text { Numeracy (number presentation, calculation) } \\
\text { Graphics (clarity of tables, charts, and graphs) }\end{array}$ & $85(87.6)$ & 0 & $7(8.2)$ & $78(91.8)$ & $95.6(14.0)$ \\
$\begin{array}{l}\text { Layout/typography (layout, typography, sub-headings, } \\
\text { organizers) }\end{array}$ & $97(100)$ & $3(11.1)$ & $7(19.40)$ & $25(69.4)$ & $80.7(32.1)$ \\
\hline
\end{tabular}

Notes. $\mathrm{SAM}+\mathrm{CAM}=$ Suitability and Comprehensibility Assessment of Materials; $\mathrm{SD}=$ standard deviation.

which have focused solely on readability. Despite the relatively high reading levels of the ICDs we analyzed, all received a SAM +CAM score of "adequate" or "superior." While this discrepancy might seem counterintuitive, SAM+CAM and SMOG measure different aspects of health literacy demand. SMOG limits its focus to readability by using a simple formula involving sentence length and polysyllabic word count; SAM $+\mathrm{CAM}$ provides a global measure of health literacy that goes well beyond readability.

Most ICDs in our study were drafted with straightforward sentences in the active voice. According to SAM $+\mathrm{CAM}$, however, their use of vocabulary helpers and confusion reducers was suboptimal, even though several IRB websites provided links to glossaries recommending substitutions for difficult words. Accordingly, these ICDs received suboptimal scores for literacy demand. Regarding layout and typography, most ICDs were scored as "adequate" rather than "superior" because of overly dense text with limited white space. Nevertheless, most used bold fonts, bullets, and headings, which can help to simplify and organize text.

We followed recommendations by the creators of SAM + CAM to treat ICDs differently from health education materials. Because ICDs do not typically include a summary, illustrations, or learning stimulation, we excluded those variables in calculating SAM+CAM. However, several studies on the acceptability of ICDs have found that pictures make consent forms more engaging (Campbell, Goldman, Boccia, \& Skinner, 2004; Institute of Medicine, 2015; Murphy, O'Keefe, \& Kaufman, 1999).

The SAM + CAM scores we calculated must be interpreted in light of the intended purposes of ICDs. The materials in our study were generally easy for people with low literacy to understand, making them suitable for documenting agreement to participate in research. However, if we assume that ICDs should also educate participants about a study, it becomes appropriate to apply the SAM+CAM categories for scoring educational materials. In that case, most of our SAM+CAM scores would have been reduced by $10 \%-22 \%$, and none of the ICDs would be considered "superior."

Both CBPR and health literacy have emerged as important factors in the conduct of research with vulnerable populations, especially in facilitating research participation (George et al, 2014). However, instead of following CBPR guidelines to foreground community empowerment, academic IRBs continue to adhere to a biomedical model of individual risks and benefits (Flicker et al., 2007; Malone, Yerger, McGruder, \& Froelicher, 2006). Their ICDs are designed to protect research institutions rather than communities. As CBPR gains recognition, institutions are advised to heed its ethical requirements in conducting research with underserved and low-literate populations. Consistent with our own findings, a recent assessment noted that few university IRBs require ICDs to describe community risks and benefits, community consent, or information about community-level control over data (Flicker et al., 2007). Although IRBs are not mandated to protect communities and should not expand their role without expertise in CBPR, some researchers have recommended that CBPR projects be approved not only by IRB representatives but also by community members.

We find it troubling that consent forms designed for community-based research with vulnerable populations received inappropriate SMOG scores and offered little acknowledgment of CBPR principles. Nevertheless, our evaluation revealed that ICDs accurately reflect the templates provided by IRBs at each Center. IRBs currently offer limited guidance for addressing health literacy and community-level ethics in the informed consent process. Even the US Office for Human Research Protections, which registers IRBs, does not provide explicit recommendations on these issues. Furthermore, despite the ready availability of models for improving informed consent, such models are not systematically recommended by IRBs.

After we completed our website assessments, two important resources for improving ICDs were published: a summary of a workshop on informed consent and health literacy sponsored by the Institute of Medicine, and a toolkit for developing ICDs from the Agency for Healthcare Research and Quality (AHRQ, 2015; Institute of Medicine, 2015). Recommendations in the toolkit encompass several SAM+CAM variables, such as writing short, simple sentences in the active voice; using headings, large fonts, and wide margins; and adding pictures to enhance engagement. Other recommended health literacy practices might also improve the consent process. For example, the teach-back 
Table 4. Health literacy criteria addressed by Institutional Review Board websites.

\begin{tabular}{|c|c|c|}
\hline Health literacy criteria provided & $\begin{array}{c}\text { Sites } \\
N\end{array}$ & Example text from IRB websites \\
\hline \multicolumn{3}{|l|}{ Reading level } \\
\hline Guidance on grade reading level & 8 & $\begin{array}{l}\text { Consent documents should be written at an } 8 \text { th grade reading level or less for the average } \\
\text { adult population. }\end{array}$ \\
\hline \multicolumn{3}{|r|}{${ }$} \\
\hline $\begin{array}{l}\text { Guidance on the purpose of the } \\
\text { document }\end{array}$ & 8 & $\begin{array}{l}\text { Start with an introductory sentence describing the primary purpose of the research as } \\
\text { stated in the protocol: State what the study is designed to discover or establish. }\end{array}$ \\
\hline \multicolumn{3}{|l|}{ Literacy demand } \\
\hline Active, direct writing style & 5 & $\begin{array}{l}\text { Whenever possible use active voice and break up the text into short straightforward } \\
\text { sections. }\end{array}$ \\
\hline Personal, conversational writing style & 3 & $\begin{array}{l}\text { Use words familiar to the audience. } \\
\text { Write consent form in conversational style, as if you were speaking to the reader. }\end{array}$ \\
\hline $\begin{array}{l}\text { Common, explicit words that are clear } \\
\text { and specific in meaning }\end{array}$ & 7 & $\begin{array}{l}\text { Lay language should be used. } \\
\text { Avoid technical or professional language used in grant submissions or with peers. }\end{array}$ \\
\hline Simple sentences & 8 & $\begin{array}{l}\text { Use short, simple, and direct sentences. } \\
\text { Use short sentences and limit paragraphs to one main idea. Average sentence length of } \\
15 \text { words or less. }\end{array}$ \\
\hline Explain or clarify difficult words & 7 & $\begin{array}{l}\text { Define terms which might not be familiar to the average person the first time they are } \\
\text { mentioned } \\
\text { Avoid research and medical jargon whenever possible. If you must use a complicated } \\
\text { term, define it in plain language and provide an example, an analogy, or a visual aid. } \\
\text { Scientific, technical, and medical terms must be defined or explained in lay terms. }\end{array}$ \\
\hline \multicolumn{3}{|r|}{ 20 } \\
\hline Use of numbers or numerical terms & 4 & $\begin{array}{l}\text { Define terms or use lay terms. Include definitions for specific research design features } \\
\text { (e.g., double-blind, randomization, placebo-controlled, dose escalation) if these will } \\
\text { help participants understand the study. }\end{array}$ \\
\hline Terms should be defined & 6 & $\begin{array}{l}\text { When describing randomization for two groups use, "like the flip of a coin," for more } \\
\text { than two groups, use "like drawing numbers from a hat." }\end{array}$ \\
\hline \multicolumn{3}{|r|}{$e_{1}$} \\
\hline Use of charts, graphs, or tables & 5 & $\begin{array}{l}\text { Use photos, graphics, or tables if they will help clarify procedures. } \\
\text { Use diagrams as helpful additions to narrative. }\end{array}$ \\
\hline \multicolumn{3}{|l|}{ Layout } \\
\hline General layout and organization & 5 & $\begin{array}{l}\text { Leave a 1-inch margin around the entire document. } \\
\text { Use of subheadings, bulleted lists, tables, flow charts, etc. to improve communication } \\
\text { and readability. }\end{array}$ \\
\hline Adequate white space & 2 & Layout balances white space with words and graphics. \\
\hline Visual cueing devices & 3 & Underline, bold, or boxes (rather than all caps or italics) to give emphasis. \\
\hline Size of font & 6 & $\begin{array}{l}12 \text { point at least, and consider larger given audience. } \\
\text { Easy to read. }\end{array}$ \\
\hline Type of font & 3 & $\begin{array}{l}\text { Use black Arial or similar font, preferably 12-point size, or larger when appropriate for } \\
\text { the study population. }\end{array}$ \\
\hline Use of headings & 4 & $\begin{array}{l}\text { Titles, subtitles, and other headers help to clarify organization of text. } \\
\text { Section headings should be in question format. }\end{array}$ \\
\hline
\end{tabular}

method, whereby participants confirm their comprehension by explaining procedures in their own words, is often cited as a strategy to improve health literacy (DeWalt et al., 2011). This strategy has been helpful in the context of surgical consent documents, making it a promising approach for future exploration (Abrams \& Earles, 2007; Lorenzen et al., 2008; Miller, Abrams, Earles, Phillips, \& McCleeary, 2011).

Despite these recommendations, incorporating principles of health literacy and CBPR in the consent process remains challenging, in part, because ICDs are currently designed as legal rather than educational documents. Our results demonstrate that the standard model for ICDs, involving pages of densely packed text without illustrations, does not promote reading comprehension. Community members have expressed preferences for illustrations and incorporating the voices of community members in consent documents (Institute of Medicine, 2015), although the effectiveness of such features and the appropriate method for implementing them require further research (Nishimura et al., 2013). Future studies should examine the effectiveness of treating ICDs as health education materials and of drafting them accordingly. 
This was the first study to evaluate IRB policies in terms of their adherence to health literacy principles. A key strength of our approach is that we went beyond readability to examine features such as layout and graphics that also affect comprehension of ICDs. We also note certain limitations. First, ICDs are only one aspect of the consent process. We did not evaluate other interactions between investigators and potential research participants. These might include providing a clear oral description of the proposed research in language understandable to members of the study community before offering any ICDs. Second, we analyzed only English-language documents, even though some studies used only Spanish-language materials in the field. Third, we limited our sample to studies supported by the Centers for Population Health and Health Disparities. Nonetheless, these Centers were specifically funded to address the needs of underserved communities and thus might be expected to optimize ICDs for use in these communities. Finally, the Centers included in our study may have used different readability tests for their documents, which may have generated lower grade-level readability scores. There are numerous tools to assess reading level, and some tools have demonstrated a variability of up to 5 reading grade levels on the same text (Wang et al, 2013). We used the SMOG readability formula because it proves to be the most reliable. Applying a standardized, valid and reliable tool, such as the SMOG, to all ICDs across IRBs would provide researchers the opportunity to evaluate their text and make necessary modifications to meet the appropriate grade-level readability.

We acknowledge the challenges experienced by investigators who need to reconcile IRB requirements with the expectations of their community partners, and we do not recommend imposing any additional barriers in this process. Research methods and processes can be very complex, making it challenging for researchers to simplify reading levels of consent forms without misleading participants. We simply advise a shift away from perceptions of ICDs as tools intended primarily to document participant consent. We encourage researchers and institutions to regard them instead as a way to educate potential study participants about the purposes, processes, and benefits of research.

\section{Acknowledgments}

We acknowledge Raymond $\mathrm{M}$. Harris, $\mathrm{PhD}$, for editing assistance and Christine Martin, Sydney Switzer, Miranda Margetts, and Mattea Grant for assistance in analyzing printed documents and institutional websites.

\section{Funding}

We acknowledge Partnerships for Native Health at the University of Washington for their support. This project was funded through a Diversity Supplement to grant U54 CA153498 (PIs: Buchwald \& Henderson) sponsored by the National Cancer Institute.

\section{References}

Aboumatar, H. J., Carson, K. A., Beach, M. C., Roter, D. L., \& Cooper, L. A. (2013). The impact of health literacy on desire for participation in healthcare, medical visit communication, and patient reported outcomes among patients with hypertension. Journal of General Internal Medicine, 28(11), 1469-1476. doi:10.1007/s11606-013-2466-5

Abrams, M. A., \& Earles, B. (2007). Developing an informed consent process with patient understanding in mind. North Carolina Medical Journal, 68(5), 352-355.

AHRQ. (2015). The AHRQ informed consent and authorization toolkit for minimal risk research. Retrieved from http://www.ahrq.gov/funding/ policies/informedconsent/

Braunstein, J. B., Sherber, N. S., Schulman, S. P., Ding, E. L., \& Powe, N. R. (2008). Race, medical researcher distrust, perceived harm, and willingness to participate in cardiovascular prevention trials. Medicine (Baltimore), 87(1), 1-9. doi:10.1097/MD.0b013e3181625d78

Brown, B. A., Long, H. L., Gould, H., Weitz, T., \& Milliken, N. (2000). A conceptual model for the recruitment of diverse women into research studies. Journal of Women's Health \& Gender-Based Medicine, 9(6), 625-632. doi:10.1089/15246090050118152

Campbell, F. A., Goldman, B. D., Boccia, M. L., \& Skinner, M. (2004). The effect of format modifications and reading comprehension on recall of informed consent information by low-income parents: A comparison of print, video, and computer-based presentations. Patient Education and Counseling, 53(2), 205-216. doi:10.1016/ S0738-3991(03)00162-9

Chen, M. S., Jr., Lara, P. N., Dang, J. H., Paterniti, D. A., \& Kelly, K. (2014). Twenty years post-NIH Revitalization Act: Enhancing minority participation in clinical trials (EMPaCT): Laying the groundwork for improving minority clinical trial accrual: Renewing the case for enhancing minority participation in cancer clinical trials. Cancer, 120(Suppl 7), 1091-1096. doi:10.1002/cncr.28575

Corbie-Smith, G., Thomas, S. B., Williams, M. V., \& Moody-Ayers, S. (1999). Attitudes and beliefs of African Americans toward participation in medical research. Journal of General Internal Medicine, 14(9), 537546. doi:10.1046/j.1525-1497.1999.07048.x

De las Nueces, D., Hacker, K., DiGirolamo, A., \& Hicks, L. S. (2012). A systematic review of community-based participatory research to enhance clinical trials in racial and ethnic minority groups. Health Services Research, 47(3 Pt 2), 1363-1386. doi:10.1111/j.1475-6773.2012.01386.x

DeWalt, D. A., Broucksou, K. A., Hawk, V., Brach, C., Hink, A., Rudd, R., \& Callahan, L. (2011). Developing and testing the health literacy universal precautions toolkit. Nursing Outlook, 59(2), 85-94. doi:10.1016/j. outlook.2010.12.002

Doak, C. C., Doak, L. G., \& Root, J. H. (1996). Teaching patients with low literacy skills Retrieved from http://www.hsph.harvard.edu/healthliteracy/resources/teaching-patients-with-low-literacy-skills/ 10.1097/ 00000446-199612000-00022

Evans, K. R., Lewis, M. J., \& Hudson, S. V. (2012). The role of health literacy on African American and Hispanic/Latino perspectives on cancer clinical trials. Journal of Cancer Education, 27(2), 299-305. doi:10.1007/s13187-011-0300-5

Flicker, S., Travers, R., Guta, A., McDonald, S., \& Meagher, A. (2007). Ethical dilemmas in community-based participatory research: Recommendations for institutional review boards. Journal of Urban Health, 84(4), 478-493. doi:10.1007/s11524-007-9165-7

Flory, J., \& Emanuel, E. (2004). Interventions to improve research participants' understanding in informed consent for research: A systematic review. JAMA: The Journal of the American Medical Association, 292 (13), 1593-1601. doi:10.1001/jama.292.13.1593

Ford, J. G., Howerton, M. W., Bolen, S., Gary, T. L., Lai, G. Y., Tilburt, J., ... Bass, E. B. (2005). Knowledge and access to information on recruitment of underrepresented populations to cancer clinical trials. AHRQ Publication No. 05-E019-1. Rockville, MD: Agency for Healthcare Research and Quality.

Ford, M. E., Siminoff, L. A., Pickelsimer, E., Mainous, A. G., Smith, D. W., Diaz, V. A., ... Tilley, B. C. (2013). Unequal burden of disease, unequal participation in clinical trials: Solutions from African American and Latino community members. Health \& Social Work, 38(1), 29-38. doi:10.1093/hsw/hlt001 
George, S., Duran, N., \& Norris, K. (2014). A systematic review of barriers and facilitators to minority research participation among African Americans, Latinos, Asian Americans, and Pacific Islanders. American Journal of Public Health, 104(2), e16-31. doi:10.2105/AJPH.2013.301706

Goodman, M., Finnegan, R., Mohadjer, L., Krenzke, T., Hogan, J., Owen, E., \& Provasnik, S. (2013). Literacy, numeracy, and problem solving in technology-rich environments among U.S. adults: Results from the program for the international assessment of adult competencies 2012. First Look. (NCES 2014-008). Retrieved from https://nces.ed.gov/pubs2014/ 2014008.pdf

Grady, C. (2015). Enduring and emerging challenges of informed consent. The New England Journal of Medicine, 372(9), 855-862. doi:10.1056/ NEJMra1411250

Hawk, E. T., Habermann, E. B., Ford, J. G., Wenzel, J. A., Brahmer, J. R., Chen, M. S., Jr., ... Vickers, S. M. (2014). Five National Cancer Institutedesignated cancer centers' data collection on racial/ethnic minority participation in therapeutic trials: A current view and opportunities for improvement. Cancer, 120(Suppl 7), 1113-1121. doi:10.1002/cncr.28571

Helitzer, D., Hollis, C., Cotner, J., \& Oestreicher, N. (2009). Health literacy demands of written health information materials: An assessment of cervical cancer prevention materials. Cancer Control: Journal of the Moffitt Cancer Center, 16(1), 70-78.

IBM Corp. (Released 2016). IBM SPSS statistics for windows, version 24.0. Armonk, NY: IBM Corp.

Institute of Medicine. (2015). Informed consent and health literacy: Workshop summary. Washington, DC: National Academies Press.

Israel, B. A., Schulz, A. J., Parker, E. A., \& Becker, A. B. (1998). Review of community-based research: Assessing partnership approaches to improve public health. Annual Review of Public Health, 19, 173-202. doi:10.1146/annurev.publhealth.19.1.173

Kass, N. E., Chaisson, L., Taylor, H. A., \& Lohse, J. (2011). Length and complexity of US and international HIV consent forms from federal HIV network trials. Journal of General Internal Medicine, 26(11), 1324-1328. doi:10.1007/s11606-011-1778-6

Kirsch, I. S., Jungeblut, A., Jenkins, L., \& Kolstad, A. (2002). Adult literacy in America: A first look at the findings of the national adult literacy survey. Washington, DC: National Center for Education Statistics.

Kutner, M., Greenberg, E., Jin, Y., \& Paulsen, C. (2006). The Health Literacy of America's Adults: Results from the 2003 National Assessment of Adult Literacy (NCES 2006-483).Washington, DC: National Center for Education Statistics.

Lorenzen, B., Melby, C. E., \& Earles, B. (2008). Using principles of health literacy to enhance the informed consent process. AORN Journal, $88(1)$, 23-29. doi:10.1016/j.aorn.2008.03.001

Malone, R. E., Yerger, V. B., McGruder, C., \& Froelicher, E. (2006). "It's like Tuskegee in reverse": A case study of ethical tensions in institutional review board review of community-based participatory research. American Journal of Public Health, 96(11), 1914-1919. doi:10.2105/AJPH.2005.082172

Margolis, D. J., Hampton, M., Hoffstad, O., Malay, D. S., \& Thom, S. (2015). Health literacy and diabetic foot ulcer healing. Wound Repair and Regeneration, 23(3), 299-301. doi:10.1111/wrr.12311

Miller, M. J., Abrams, M. A., Earles, B., Phillips, K., \& McCleeary, E. M. (2011). Improving patient-provider communication for patients having surgery: Patient perceptions of a revised health literacy-based consent process. Journal of Patient Safety, 7(1), 30-38. doi:10.1097/ PTS.0b013e31820cd632

Mosenthal, P. B., \& Kirsch, I. S. (1998). A new measure for assessing document complexity; The PMOSE/IKIRSCH document readability formula. Journal of Adolescent \& Adult Literacy, 41, 638-657.

Moser, D. K., Robinson, S., Biddle, M. J., Pelter, M. M., Nesbitt, T. S., Southard, J., ... Dracup, K. (2015). Health literacy predicts morbidity and mortality in rural patients with heart failure. Journal of Cardiac Failure, 21(8), 612-618. doi:10.1016/j.cardfail.2015.04.004

Murphy, D. A., O'Keefe, Z. H., \& Kaufman, A. H. (1999). Improving comprehension and recall of information for an HIV vaccine trial among women at risk for HIV: Reading level simplification and inclusion of pictures to illustrate key concepts. AIDS Education and Prevention, 11 (5), 389-399.

National Center for Education Statistics. (2003). National assessment of adult literacy. Retrieved from http://nces.ed.gov/naal/kf_demographics.asp

National Center for Education Statistics. (2013). Program for the international assessment of adult competencies. Retrieved from http://nces.ed. gov/surveys/piaac/

Nishimura, A., Carey, J., Erwin, P. J., Tilburt, J. C., Murad, M. H., \& McCormick, J. B. (2013). Improving understanding in the research informed consent process: A systematic review of 54 interventions tested in randomized control trials. BMC Medical Ethics, 14, 28. doi:10.1186/1472-6939-14-28

Paasche-Orlow, M. K., Taylor, H. A., \& Brancati, F. L. (2003). Readability standards for informed-consent forms as compared with actual readability. The New England Journal of Medicine, 348(8), 721-726. doi:10.1056/NEJMsa021212

Paskett, E. D., Reeves, K. W., McLaughlin, J. M., Katz, M. L., McAlearney, A. S., Ruffin, M. T., ... Gehlert, S. (2008). Recruitment of minority and underserved populations in the United States: The Centers for Population Health and Health Disparities experience. Contemporary Clinical Trials, 29(6), 847-861. doi:10.1016/j.cct.2008.07.006

Putnam, L. R., Chang, C. M., Rogers, N. B., Podolnick, J. M., Sakhuja, S., Matusczcak, M., ... Tsao, K. (2015). Adherence to surgical antibiotic prophylaxis remains a challenge despite multifaceted interventions. Surgery, 158(2), 413-419. doi:10.1016/j.surg.2015.04.013

Quinlan, P., Price, K. O., Magid, S. K., Lyman, S., Mandl, L. A., \& Stone, P. W. (2013). The relationship among health literacy, health knowledge, and adherence to treatment in patients with rheumatoid arthritis. HSS Journal, 9(1), 42-49. doi:10.1007/s11420-012-9308-6

Schillinger, D., Grumbach, K., Piette, J., Wang, F., Osmond, D., Daher, C., ... Bindman, A. B. (2002). Association of health literacy with diabetes outcomes. JAMA: The Journal of the American Medical Association, 288(4), 475-482. doi:10.1001/jama.288.4.475

Schmotzer, G. L. (2012). Barriers and facilitators to participation of minorities in clinical trials. Ethnicity \& Disease, 22(2), 226-230.

Seifer, S. D., Michaels, M., \& Collins, S. (2010). Applying communitybased participatory research principles and approaches in clinical trials: Forging a new model for cancer clinical research. Progress in Community Health Partnerships: Research, Education, and Action, 4 (1), 37-46. doi:10.1353/cpr.0.0103

Simonds, V. W., Wallerstein, N., Duran, B., \& Villegas, M. (2013). Community-based participatory research: Its role in future cancer research and public health practice. Preventing Chronic Disease, 10, E78. doi: $10.5888 / \mathrm{pcd} 10.120205$

Sudore, R. L., Landefeld, C. S., Williams, B. A., Barnes, D. E., Lindquist, K., \& Schillinger, D. (2006). Use of a modified informed consent process among vulnerable patients: A descriptive study. Journal of General Internal Medicine, 21(8), 867-873. doi:10.1111/j.1525-1497.2006.00535.x

Tattersall, M. H. (2001). Examining informed consent to cancer clinical trials. The Lancet, 358(9295), 1742-1743. doi:10.1016/S0140-6736(01)06838-6

Terblanche, M., \& Burgess, L. (2010). Examining the readability of patientinformed consent forms. Open Access Journal of Clinical Trials, 2, 157162. doi:10.2147/OAJCT.S13608

Terranova, G., Ferro, M., Carpeggiani, C., Recchia, V., Braga, L., Semelka, R. C., \& Picano, E. (2012). Low quality and lack of clarity of current informed consent forms in cardiology: How to improve them. JACC. Cardiovascular Imaging, 5(6), 649-655. doi:10.1016/j.jcmg.2012.03.007

Trantham, L. C., Carpenter, W. R., DiMartino, L. D., White, B., Green, M., Teal, R., ... Godley, P. A. (2015). Perceptions of cancer clinical research among African American Men in North Carolina. Journal of the National Medical Association, 107(1), 33-41. doi:10.1016/S0027-9684(15)30007-9

Wang, L. W., Miller, M. J., Schmitt, M. R., \& Wen, F. K. (2013). Assessing readability formula differences with written health information materials: Application, results, and recommendations. Research in Social and Administrative Pharmacy, 9(5), 503-516. doi:10.1016/j. sapharm.2012.05.009 